\title{
Induction-Motor Field Efficiency Evaluation Using Instantaneous Phasor Method (Abstract)
}

\section{Abstract}

The new instantaneous phasor method originated by the author is applied for the evaluation of efficiency of induction motors installed in the field.

John S. Hsu

Senior Member

RECEIVED

MAR O 61998

O STI

Oak Ridge National Laboratory

Post Office Box 2009, MS 8038

Oak Ridge, Tennessee 37831-8038

Phone: (423) 241-5045

Fax: (423) 241-6124

Email: hsujs@ornl.gov

DISTAIBUTION OF THIS DOCUMENT IS UNLIMTED

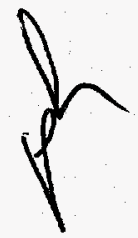




\section{DISCLAIMER}

This report was prepared as an account of work sponsored by an agency of the United States Government. Neither the United States Government nor any agency thereof, nor any of their employees, makes any warranty, express or implied, or assumes any legal liability or responsibility for the accuracy, completeness, or usefulness of any information, apparatus, product, or process disclosed, or represents that its use would not infringe privately owned rights. Reference herein to any specific commercial product, process, or service by trade name, trademark, manufacturer, or otherwise does not necessarily constitute or imply its endorsement, recommendation, or favoring by the United States Government or any agency thereof. The views and opinions of authors expressed herein do not necessarily state or reflect those of the United States Government or any agency thereof. 


\section{DISCLAIMER}

Portions of this document may be illegible in electronic image products. Images are produced from the best available original document. 


\title{
Induction-Motor Field Efficiency Evaluation Using Instantaneous Phasor Method (Abstract \& Digest)
}

\author{
John S. Hsu \\ Senior Member \\ Oak Ridge National Laboratory* \\ Post Office Box 2009, MS 8038 \\ Oak Ridge, Tennessee 37831-8038
}

Key words: Efficiency, Induction motors, Instantaneous phasors, Field evaluation, Method,

\section{Abstract}

The new instantaneous phasor method originated by the author is applied for the evaluation of efficiency of induction motors installed in the field.

\section{DIGEST}

Induction motors are the most commonly used motors in industry. They are important components in the chains of drive systems. Motor efficiency is the ratio of shaft output power to motor input power. IEEE Std 112 [1] presents many methods for induction-motor efficiency tests that may not all be suitable for field efficiency evaluations.

When the balanced power supply contains negligible harmonics, various modified versions based on Method E1 of the IEEE Std 112 [1] can be quite accurate for conventional induction motor field efficiency evaluations.

An unrealistic interpretation of Method $\mathrm{E}$ is that under any motor load, the losses produced by the negative fields associated with unbalanced supply voltages and harmonics are accurately represented by the no-load loss. These negative sequence fields are assumed to be nearly constant over the entire load range, because the speed difference between full load and no load is small. Consequently, the slip variation is minute and the negative sequence impedance as well as the negative sequence currents remain the same. From this interpretation it follows that under any load the loss associated with the negative sequence fields is the same as this loss at no load. This leads to the interpretation that the effects of unbalanced voltages and harmonics are fully covered in Method E.

This interpretation is incorrect for motors operating in the field. In the real world there is supply impedance. The motor terminal voltages do change a little as the load varies. The tested fundamental frequency voltages and, in particular, the currents of the positive and negative sequence components change at different loads under an unbalanced supply $[2,3]$. The no load loss does not represent the negative sequence losses when the motor is loaded.

In Method $\mathrm{E}$ the input power is used as the base to subtract various losses for the output power. The negative sequence losses that are not completely represented by the no load loss increase the input power. Consequently, the estimated output power is higher. The air-gap-torque method [2,3] presented by the author overcomes this problem.

The undesirable effect of negative-sequence voltages and currents can be evaluated through an alternative approach. This paper presents an example that uses the instantaneous phasor method $[4,5]$ originated by the author to evaluate efficiencies of induction motors installed in the field.

The instantaneous phasors of voltages and currents derived in [4] can either be presented in a vector format or in a complex number format. The arbitrarily chosen complex number format of the instantaneous phasors, such as the voltages, $V_{a}, V_{b}$, and $V_{c}$, are given in (1). They have the same magnitude but are 120-degrees apart.

\footnotetext{
Prepared by the Oak Ridge National Laboratory, Oak
Department of Energy under contract DE-AC05-96OR22464.

The submitted manuscript has been authored by a contractor of the U S Govemment under contract No DE-AC05-960R22464 Accordingly, the U.S. Government retains a nonexclusive, royalty-free license to publish or reproduce the published form of this contribution, or allow others to do so, for U. S. Government purposes.
} 


$$
\begin{aligned}
& V_{a}=\left(v_{a}-v_{0}\right)+j v_{a q}, \\
& V_{b}=\left(v_{b}-v_{0}\right)+j v_{b q}, \text { and } \\
& V_{c}=\left(v_{c}-v_{0}\right)+j v_{c q} .
\end{aligned}
$$

where the zero-sequence component for the three-phase voltages is

$$
v_{0}=\frac{1}{3}\left(v_{a}+v_{b}+v_{c}\right)
$$

The real values of the instantaneous phasors are simply the instantaneous phase values with the zerosequence component subtracted as given in (3).

$$
\begin{aligned}
& \left(v_{a}-v_{0}\right), \\
& \left(v_{b}-v_{0}\right), \text { and } \\
& \left(v_{c}-v_{0}\right) .
\end{aligned}
$$

The instantaneous phasors' imaginary values denoted as $v_{a q}, v_{b q}$, and $v_{c q}$ can be obtained from (4)

$$
\begin{aligned}
& v_{a q}=\frac{v_{b}-v_{c}}{\sqrt{3}}, \\
& v_{b q}=\frac{v_{c}-v_{a}}{\sqrt{3}}, \quad \text { and } \\
& v_{c q}=\frac{v_{a}-v_{b}}{\sqrt{3}} .
\end{aligned}
$$

The numerators of equation (4) are actually the instantaneous line to line voltages that are not affected by the zero-sequence component.

The instantaneous phasor magnitude, $V$, of $V_{a}, V_{b}$, and $V_{c}$ can be derived from (4), (3), and (2). The result is that

$$
\left\|V_{a}\right\|=\left\|V_{b}\right\|=\left\|V_{c}\right\|=V
$$

where

$$
V=\sqrt{\frac{2}{9}\left[\left(v_{a}-v_{b}\right)^{2}+\left(v_{b}-v_{c}\right)^{2}+\left(v_{c}-v_{a}\right)^{2}\right]}
$$

Alternatively, the instantaneous phasor magnitude, $V$, of $V_{a}, V_{b}$, and $V_{c}$ can be derived from a phase, for instance, phase-a.

$$
V=\sqrt{\left(v_{a}-v_{0}\right)^{2}+v_{a q}^{2}} .
$$

The field tested voltages and currents at full load of a 7.5-hp, 4-pole induction motor are shown as follows. The voltages are slightly unbalanced, and the currents are significantly more unbalanced.
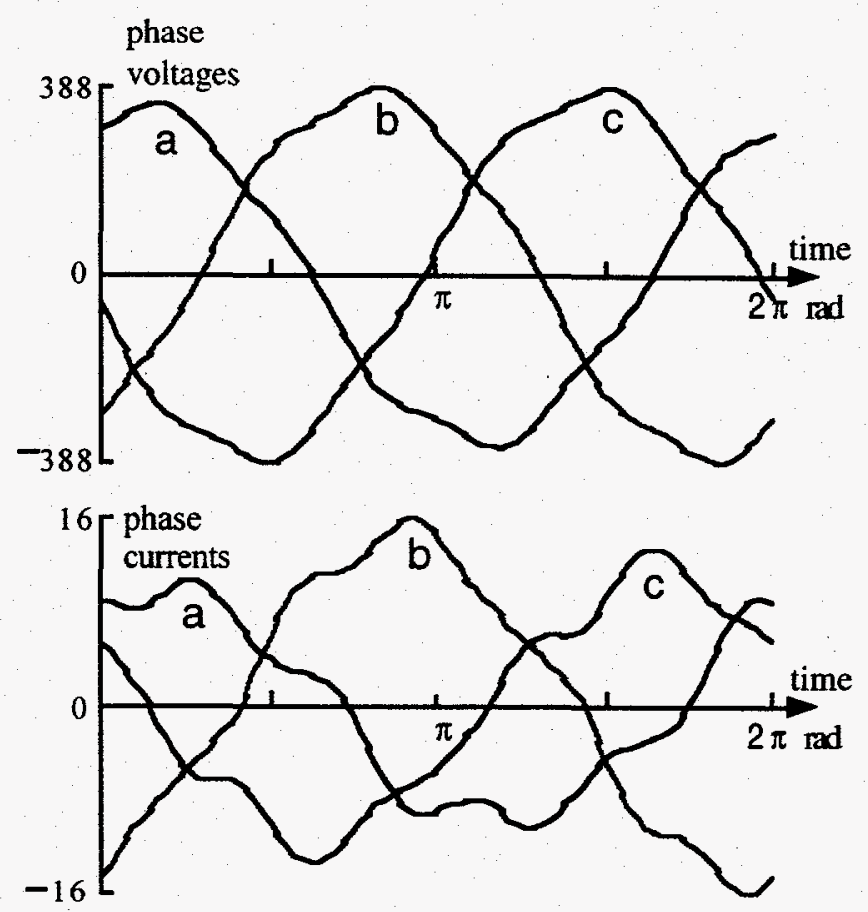

Fig. 1 Phase voltages and currents at full load

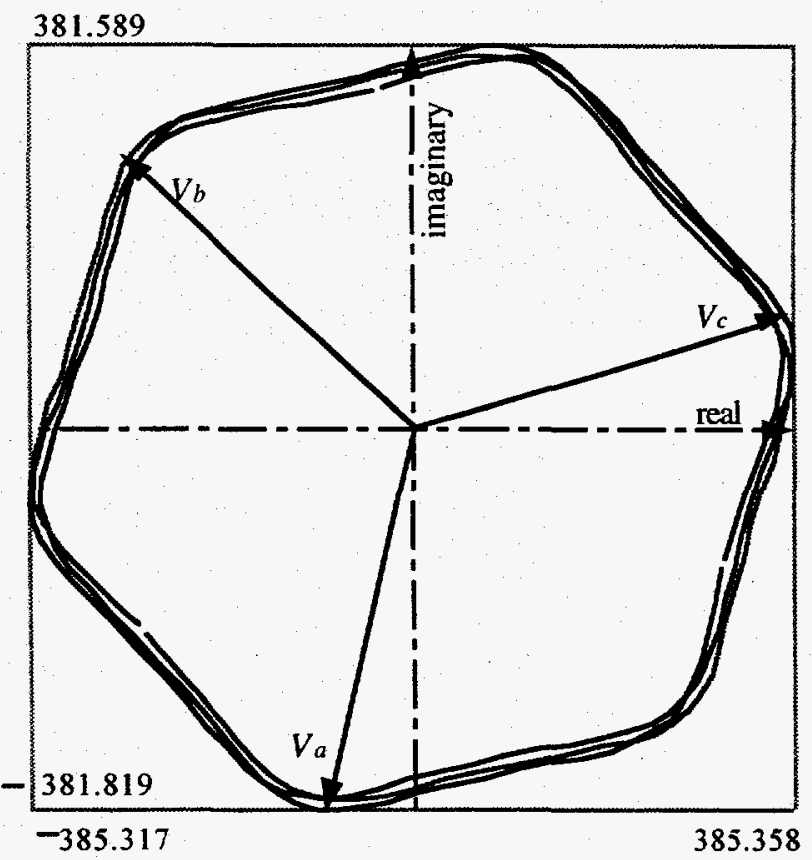

Fig. 2 Trajectory of instantaneous phasors, $V_{a}, V_{b}$, and $V_{c}$, at full load 
The trajectories of instantaneous voltage phasors, $V_{a}, V_{b}$, and $V_{c}$, of (1) for the motor at full load are shown in Fig. 2, where the three phasors are always identical in magnitude and with 120-degree phase shift from each other. The same observations can be drawn from the trajectories of instantaneous current phasors, $i_{a}, i_{b}$, and $i_{c}$, shown in Fig. 3.

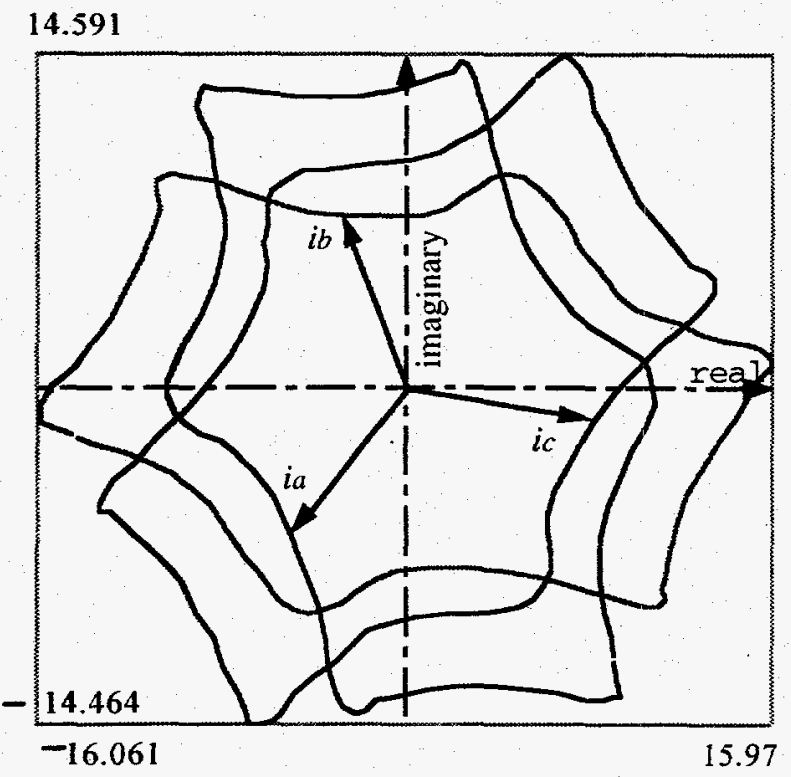

Fig. 3 Trajectory of instantaneous current phasors, $i_{a}, i_{b}$, and $i_{c}$, at full load

Figs. 2 and 3 also show that for polluted voltages and currents the instantaneous phasor trajectories are not circles because of harmonics and negative-sequence contents. The instantaneous phasors are not rotating at a constant speed $[4,5]$. The six peaks shown in the current trajectory suggest a strong fifth or seventh harmonic content

The unique property of the instantaneous phasors of three phases is that the phasors have the same magnitude but are separated by 120 -degrees. This permits taking the voltage and current phasors of one phase to calculate the various powers of the entire motor.

The fundamental voltage and current phasors of phase a are given in Figs. 4 and 5. They are not in perfect circles because of the unbalanced voltages and currents [5]. Their positive and negative-sequence components can be obtained simply by the maximum and the minimum magnitudes of the instantaneous phasors, respectively. As an example, the positive and negative-sequence trajectories [5] of the current instantaneous phasor are illustrated in Fig. 5. Subsequently, the positive-sequence power and negative-sequence power, which equals the fundamental- frequency power obtained from the phasors minus the positive-sequence power, can be obtained.

Other harmonic powers, such as the fifth harmonic power can also be obtained in a like manner as demonstrated for the fundamental-frequency powers.

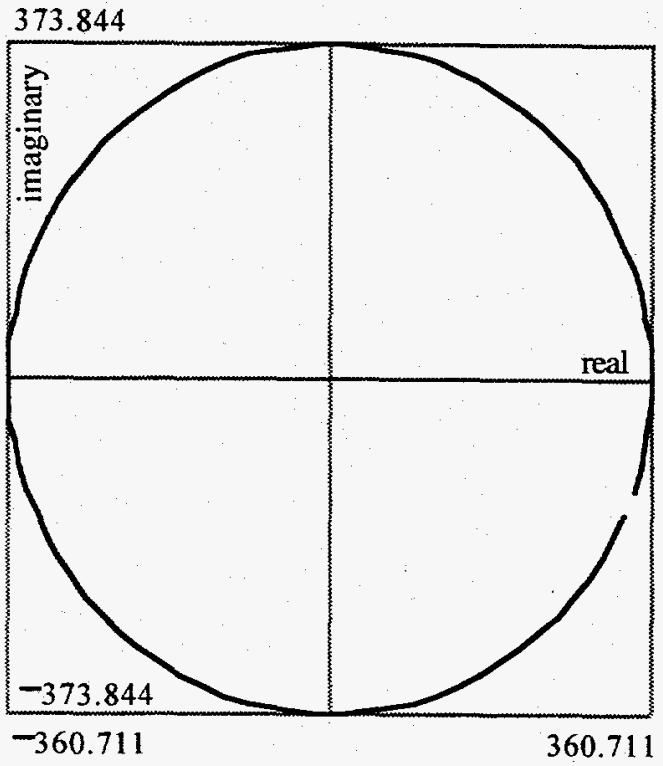

Fig. 4 Fundamental-frequency, phase-a voltage instantaneous phasor trajectory

phase-a

instantaneous

current phasor

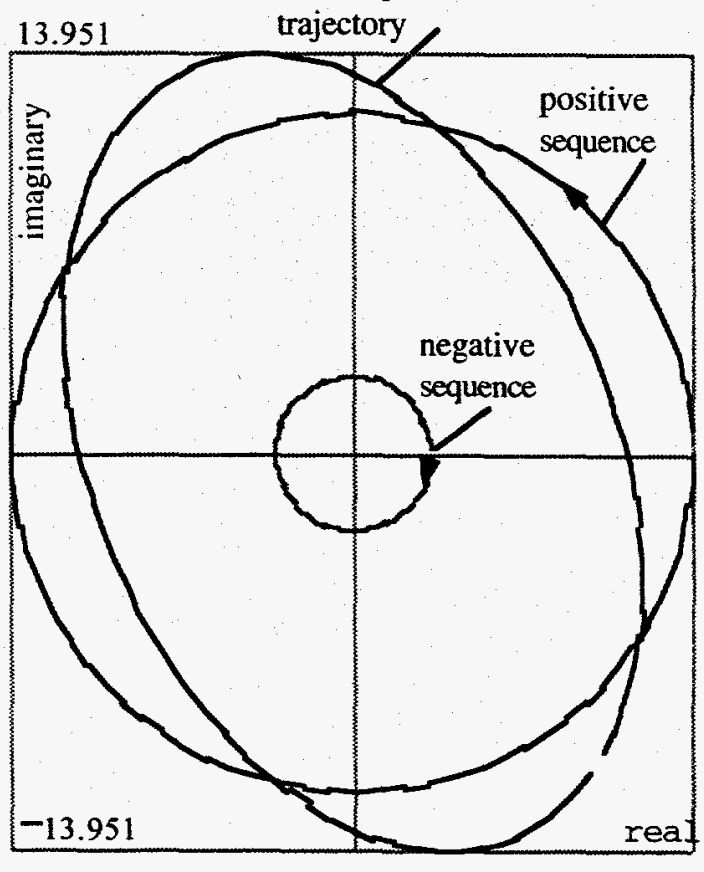

$-11.883$

11.883

Fig. 5 Fundamental-frequency, phase-a current instantaneous phasor trajectory 
It is reasonable to assume that the three phases of a three-phase induction motor are basically balanced. At the fundamental-frequency, negative-sequence power produces an opposite torque that is not helping the useful output, and can be considered as a loss. The fifth-harmonic and all the other normally small negative-sequence harmonics power produce similar losses. The zerosequence power also produces no useful power. Therefore, the output power of an induction motor is the input power minus the stator copper loss, the fundamental-frequency negative-sequence power, the fifth harmonic and other negative-sequence harmonics ( $8 \mathrm{th}, 11 \mathrm{th}$, etc.) power, the zero-sequence power, the core and friction losses that are either obtained from no-load or from estimation, and the rotor copper loss estimated by the rotor slip that is measured from a speedometer. A certain stray loss that needs to be evaluated statistically should also be considered for the output evaluation. Efficiency is the ratio of the motor output to the motor input power.

Estimated and statistical data are normally used if the required data cannot be practically obtained. However, the accuracy of the evaluation diminishes when fewer measurements are taken.

Fig. 6 shows the comparison between the efficiencies that are measured by the torque gauge and the efficiencies obtained from the instantaneous phasor method at different loads. A reasonably good agreement is observed. The motor being tested is a 7.5-hp, 4-pole induction motor. The three-phase supply voltages are slightly unbalanced. Since no stray-load loss has been taken into account in the evaluation, the efficiencies obtained from the instantaneous phasor method are slightly higher than the efficiencies obtained from the torque-gauge method.

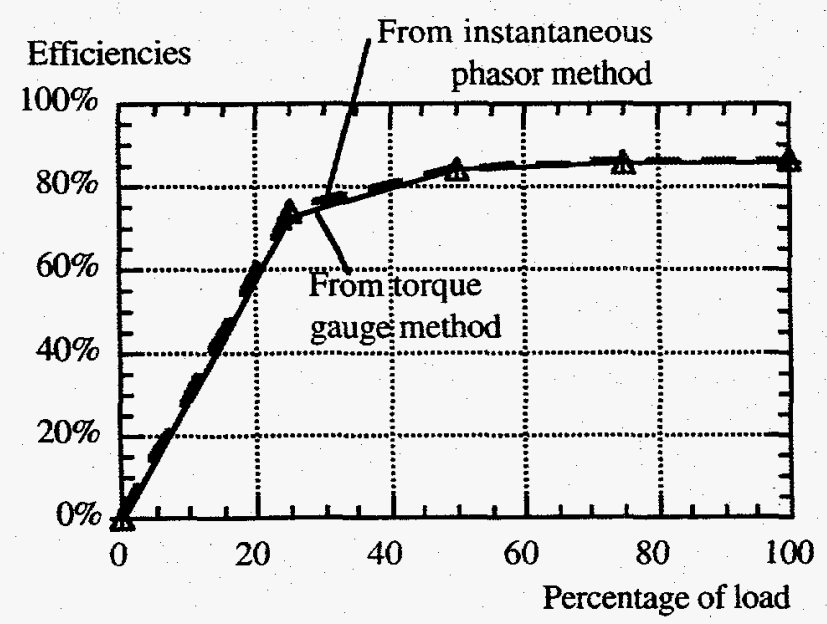

Fig. 6 Comparison between efficiencies measured by torque gauge and efficiencies obtained from the instantaneous phasor method at different loads.

\section{REFERENCES}

[1] IEEE Standard Test Procedure for Polyphase Induction Motors and Generators, IEEE Std 112-1991, IEEE Power Engineering Society, New York, NY.

[2] John S. Hsu, J. D. Kueck, M. OLszewski, D. A. Casada, P. J. Otaduy, and L. M. Tolbert, " Comparison of Induction Motor Field Efficiency Evaluation Methods," Paper No. EMC-1-6-6, IEEE/LAS 31st Annual Meeting, October 5-10, 1996, San Diego, CA.

[3] John S. Hsu and Patrick L. Sorenson, "Field Assessment of Induction Motor Efficiency through Air-Gap Torque," paper No. 96WM-130-5EC, presented at the IEEE/PES Winter Meeting, January 21-25, 1996, Baltimore, MD, and accepted for publication in IEEE Transactions on Energy Conversion.

[4] John S. Hsu, "Instantaneous Phasor Method for Obtaining Instantaneous Balanced Fundamental Components for Power Quality Control and Continuous Diagnostics," Paper Number: 98WM360, Power Engineering Society Winter Meeting, 1998, Tampa, FL.

[5] John S. Hsu, "Instantaneous Phasor Method Under Severely Unbalanced Situations," Paper Number: 98SM202, Power Engineering Society Summer Meeting, 1998, San Diego, CA. 